\title{
Gastroenteropatía perdedora de proteínas y posible relación con una infección por citomegalovirus. Presentación de un caso de enfermedad de Ménétrier infantil
}

\author{
Protein losing gastroenteropathy and possible relationship to cytomegalovirus \\ infection. Ménétrier disease in a child
}

\author{
Dra. María M. Hillman ${ }^{a}$, Dr. Leonardo L. Meinarde ${ }^{a}$ Dra. Raquel A. Furnes ${ }^{b}$, Dra. María L. Daruich ${ }^{b}$ \\ Dra. Verónica Rivac y Dr. Eduardo Cuestas ${ }^{a}$
}

\begin{abstract}
RESUMEN
La enfermedad de Ménétrier infantil es una gastroenteropatía perdedora de proteínas caracterizada por hipertrofia de la mucosa gástrica, de causa desconocida, aunque la mayoría de los casos informados se han asociado a infecciones virales. Se manifiesta clínicamente por edema y bioquímicamente por hipoproteinemia e hipoalbuminemia. Es poco común en los niños, en quienes tiene un carácter benigno y autolimitado, a diferencia de los adultos, en los que tiende a cronificarse y, en ocasiones, a malignizarse. Se presenta un caso de enfermedad de Ménétrier infantil con síndrome ascítico edematoso posiblemente asociado a una infección por citomegalovirus. Palabras clave: enfermedad de Ménétrier, gastroenteropatía perdedora de proteinas, sindromeascíticoedematoso, citomegalovirus.
\end{abstract}

\begin{abstract}
Ménétrier's disease is a childhood protein-losing gastroenteropathy characterized by hypertrophy of the gastric mucosa, of unknown etiology, although most of reported cases have been associated with viral infections. Clinical manifestation is edema and biochemically there are hypoproteinemia and hypoalbuminemia. This disease is very rare in children and they have a benign and self-limiting course in contrast to adults where tend to be chronic and occasionally to become malignant. We present a child with Ménétrier disease with edema and ascites possibly associated with a cytomegalovirus infection. Key words: Ménétrier's disease, protein-losing gastroenteropathy, ascitic syndrome edematous, cytomegalovirus.
\end{abstract}

http:/ /dx.doi.org/10.5546/aap.2013.e121

\section{INTRODUCCIÓN}

La enfermedad de Ménétrier fue descrita por vez primera en 1888 por el patólogo francés Pierre Eugene Ménétrier en pacientes adultos. La forma

a. Servicio de Pediatría y Neonatología.

b. Sección de Gastroenterología y Nutrición.

c. Servicio de Anatomía Patológica.

Hospital Privado Centro Médico de Córdoba.

Correspondencia:

Dra. Hillman María M: macahillman@hotmail.com

Conflicto de intereses: Ninguno que declarar.

Recibido: 4-12-2012

Aceptado: 16-7-2013 infantil, de descripción mucho más reciente, se caracteriza por su rareza (60 casos publicados hasta el momento), inicio agudo, curso benigno y carácter autolimitado. La mayoría de los casos se asocian a infecciones, especialmente virales. Se piensa que los virus podrían perturbar los factores que modulan el crecimiento y la función de las células gástricas. Cursa clínicamente con vómitos, anorexia, dolor abdominal, astenia, diarrea, pérdida de peso y edemas causados por hipoalbuminemia, consecuencia de la pérdida de proteínas por la mucosa gástrica. La ecografía y la endoscopia muestran agrandamiento de la mucosa gástrica, hipertrofia de los pliegues y presencia de quistes glandulares. El tratamiento es sintomático y presenta buena evolución, con curación completa.

Se presenta el caso de un niño de 30 meses con enfermedad de Ménétrier infantil secundaria, posiblemente, a una infección por citomegalovirus.

\section{CASO CLÍNICO}

Niño de 30 meses, nacido a término, cesárea programada, embarazo controlado, peso y talla acordes con la edad gestacional. Antecedentes de dos episodios de otitis media, sin cirugías, internaciones previas ni alergias. Inmunizaciones completas según el calendario oficial. Crecimiento y desarrollo normales. Historia familiar con ambos padres obesos con cirugía bariátrica realizada, y dos hermanas mayores con antecedentes de asma e hipotiroidismo, respectivamente.

Es derivado a nuestro hospital con diagnóstico de síndrome ascítico edematoso. Comenzó una semana antes con un edema palpebral bilateral leve. Dos días después, presentó un exantema urticariante generalizado en todo el cuerpo, no pruriginoso, que revirtió espontáneamente en menos de 24 horas. A las 48 horas, apareció un edema bipalpebral más pronunciado, 
distensión abdominal e irritabilidad. Se consultó al pediatra, que constató un aumento de $2 \mathrm{~kg}$ con respecto a peso previo ( 2 meses antes). No tenía antecedentes de infecciones. Fue derivado a un médico nefrólogo, quien solicitó estudios de laboratorio cuyos resultados mostraron marcada hipoproteinemia e hipoalbuminemia, hipertrigliceridemia, hipocalcemia leve y orina normal. Se trasladó al niño a nuestro hospital para su diagnóstico y tratamiento.

Examen físico: niño lúcido, vigil, orientado, irritable. TA 109/78 mm Hg, TAM $92 \mathrm{~mm}$ $\mathrm{Hg}, \mathrm{FC} 130 \mathrm{lpm}, \mathrm{FR} 32 \mathrm{rpm}$, temperatura $36,7^{\circ} \mathrm{C}$, saturación de $\mathrm{O}_{2} 96 \%$ respirando aire ambiente. Peso 14,600 kg, palidez generalizada, facies abotagada. Edema palpebral bilateral. Algunos crepitantes basales en ambos campos pulmonares. Edema pretibial bilateral. Abdomen globuloso, distendido, onda ascítica positiva, sin hepatoesplenomegalia. Edema escrotal y suprapúbico. El resto del examen no presentó particularidades.

Laboratorio inicial: leucocitos: $17700 / \mathrm{mm}^{3}$, fórmula: $27 \%$ neutrófilos, $14 \%$ eosinófilos, $49 \%$ linfocitos, $6 \%$ monocitos y $4 \%$ linfocitos atípicos. Calcio total 7,4 mmol/L (VN 8,5-10), proteínas totales $3 \mathrm{~g} / \mathrm{dl}$ (VN 6,6-8,7), albúmina 1,6 g/dl (VN 3,5-3), IgG 136 mg/dl (VN 490-1450), IgE $140 \mathrm{UI} /$ $\mathrm{ml}$ (VN hasta 75), triglicéridos $196 \mathrm{mg} / \mathrm{dl}(\mathrm{N}<150)$, TGO $62 \mathrm{U} / \mathrm{L}(\mathrm{VN}<37)$, TGP $43 \mathrm{U} / \mathrm{L}(\mathrm{VN}<41)$, colesterol total $129 \mathrm{mg} / \mathrm{dl}(\mathrm{VN}<200), \mathrm{HDL} 25 \mathrm{mg} /$ $\mathrm{dl}(\mathrm{VN}>35)$. PCR $1,3 \mathrm{mg} / \mathrm{dl}(\mathrm{VN}<0,06)$. Orina normal sin proteinuria. Relación Prot/Cr 0,26. Hormonas tiroideas normales y anticuerpos para enfermedad celíaca negativos. Prueba de la tuberculina negativa.

Al segundo día de internación, el niño presentó dos picos febriles, fauces congestivas, subcrepitantes pulmonares bibasales leves. Radiografía de tórax y ecografía renal sin particularidades. Ecografía abdominal sin visceromegalia, con líquido ascítico moderado, mucosa gástrica sin agrandamiento ni hipertrofia de pliegues.

Se descartó la etiología cardiovascular, renal o hepática por la clínica y los estudios realizados.

Ante la sospecha de gastroenteropatía perdedora de proteínas, se realizó una endoscopia esofagogastroduodenal con biopsia, cuyo informe reveló: esófago con cambio mucoso a $23 \mathrm{~cm}$, mucosa pálida y muy edematosa; estómago con presencia de pliegues engrosados, seudopólipos y erosiones de la mucosa (Figura 1). Duodeno con pliegues engrosados y mucosa edematosa. El informe de la biopsia correspondió a esofagitis, gastritis y duodenitis crónica leve a moderada con frecuentes eosinófilos (Figura 2). No se realizó depuración de $\alpha_{1}$-antitripsina por la falta de accesibilidad al método.

Se solicitó en sangre, IgM-IgG para CMV:

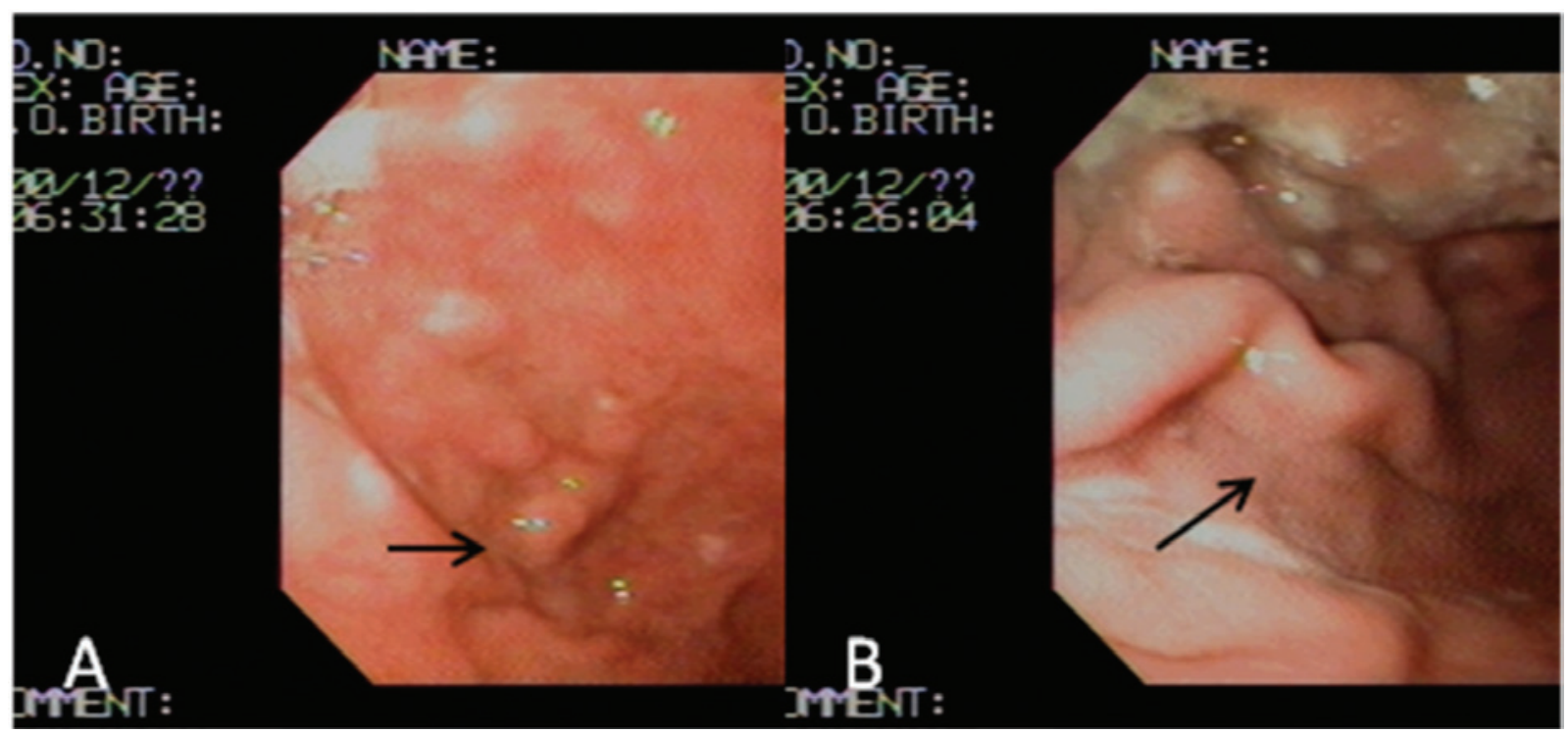


positivo; antígeno temprano: reactivo; PCR: 2075 copias (no reactivo $<750$ copias). No se analizó material de biopsia para la detección del virus.

El paciente fue sometido a una dieta hiperproteica y gastroprotectora. Recibió una infusión intravenosa de albúmina $(25 \% 1 \mathrm{~g} /$ $\mathrm{kg}$, una dosis), omeprazol $20 \mathrm{mg}$ /día por vía intravenosa y espironolactona $3 \mathrm{mg} / \mathrm{kg} /$ día por vía oral. Al no mejorar clínicamente, a los 6 días se comenzó la administración de ganciclovir por vía intravenosa ( $5 \mathrm{mg} / \mathrm{kg}$ cada 12 horas). A las 48 horas se rotó a valganciclovir oral (400 mg/día) por la imposibilidad de mantener la venoclisis.

A los 10 días de internación, dada la buena evolución, se le otorgó el alta hospitalaria. Laboratorio al alta: proteínas totales 4,6 g/ dl (VN 6,6-8,7), albúmina 2,6 g/dl (VN 3,5-5), triglicéridos $254 \mathrm{mg} / \mathrm{dl}(\mathrm{VN}<150)$. Carga viral para CMV $<750$ copias. Se indicó continuar con dieta hiperproteica, protectores gástricos y valganciclovir por vía oral hasta completar 6 semanas de tratamiento. Cuatro meses después, se repitió la endoscopia esofagogastroduodenal, cuyo resultado fue normal.

\section{DISCUSIÓN}

La enfermedad de Ménétrier, en su forma infantil, es una entidad rara; se sabe poco de ella a través de los aproximadamente 60 casos informados hasta el momento. ${ }^{1,2}$ En los adultos se presenta como una patología crónica y con riesgo de malignización; ${ }^{3}$ en los niños se caracteriza por un inicio brusco, evolución benigna, autolimitada, y duración aproximada de 5 a 6 semanas.

A nivel histopatológico se presenta como una gastroenteropatía perdedora de proteínas con hiperplasia e hipertrofia glandular, aumento de la secreción mucosa y de la permeabilidad, predominantemente en el cuerpo y el fondo del estómago.

Clínicamente se manifiesta con edema y síntomas inespecíficos gastrointestinales: diarrea, hiperemesis, anorexia y pérdida de peso. Pueden existir síntomas prodrómicos virales. En las pruebas bioquímicas cursa con hipoproteinemia sin proteinuria, hipoalbuminemia, hipertrigliceridemia, hipogammaglobulinemia y linfopenia. También malabsorción de grasas y vitaminas liposolubles, disminución de la secreción ácida y de la concentración sérica de colesterol, $\alpha_{1}$-antitripsina, fibrinógeno y ceruloplasmina.

La etiopatogenia es poco conocida. Las teorías etiológicas propuestas incluyen mecanismos alérgicos, autoinmunitarios e infecciosos; en este último caso se ha asociado con citomegalovirus (CMV), especies del virus del herpes simple. Existe cierta evidencia de que los agentes infecciosos estimularían los receptores del factor de crecimiento epidérmico (REGF) que, a su vez, a través de una tirosina-cinasa, activaría al factor

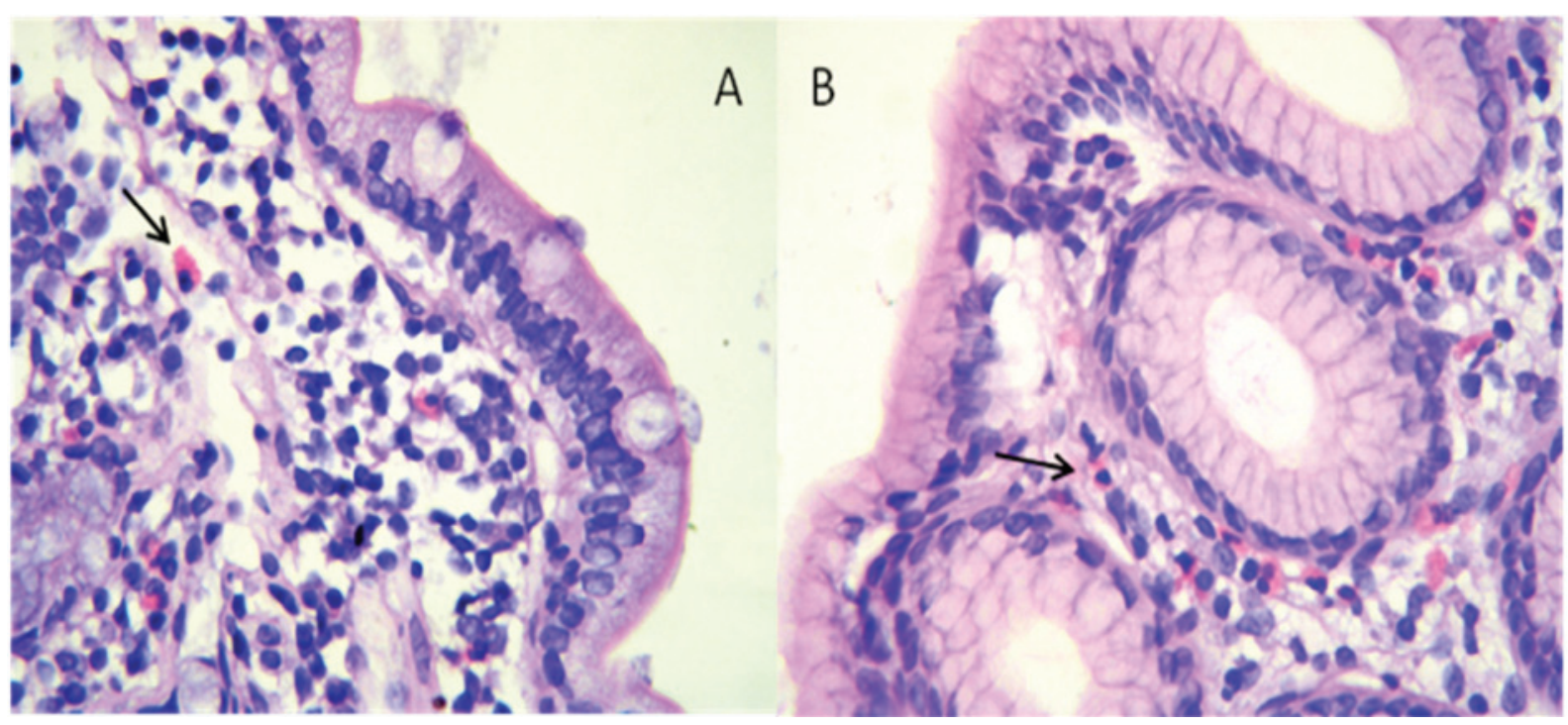


de crecimiento transformante alfa (TGF- $\alpha$ ), que estimularía el crecimiento de células epiteliales mucosas y disminuiría la secreción gástrica. Se sugirió que CMV puede ser el principal causante de la enfermedad en los niños. Las células infectadas podrían interactuar con los REGF y activar así el procedimiento descrito. ${ }^{4-9}$

Para el diagnóstico se deben descartar todas las causas de pérdida de proteínas, como enfermedad hepática, desnutrición grave, síndrome nefrótico, malformaciones del sistema linfático intestinal, $y$ otras enfermedades que incluyen gastritis eosinofílica, gastritis alérgica, síndrome de Zollinger-Ellison, linfoma gástrico y carcinoma infiltrativo.

Se puede objetivar la pérdida específica de proteínas del tubo digestivo mediante la depuración de $\alpha_{1}$-antitripsina sérica. El tránsito esofagogastroduodenal pone en evidencia el engrosamiento de los pliegues con predominio en el fondo y el cuerpo gástricos. La endoscopia digestiva alta con toma de biopsia muestra hipertrofia e hiperplasia; proliferación, elongación y dilatación quística de las glándulas, y discreta a moderada eosinofilia.

La infección por CMV en los niños puede ser congénita, perinatal o adquirida. Los métodos serológicos sólo sirven como pruebas de detección. El anticuerpo IgM CMV puede permanecer meses en la sangre y esto hace que no pueda establecerse que el virus es la causa de la enfermedad. El diagnóstico se realiza con la detección inmunohistoquímica del antígeno nuclear temprano de CMV en el material de biopsia gástrica. Algunos autores consideran posible la detección de cuerpos de inclusión de CMV en las células epiteliales. ${ }^{6,10}$ La PCR y la carga viral son métodos más sensibles que las pruebas serológicas y ayudarían a establecer el diagnóstico.

En general, los casos de enfermedad de Ménétrier en los niños son autolimitados y el tratamiento es de sostén: dieta rica en proteínas y baja en grasas; protectores gástricos, como los inhibidores de la bomba de protones o los bloqueantes de los receptores $\mathrm{H} 2$; anticolinérgicos; reposición de albúmina y diuréticos. El CMV podría no tratarse con ganciclovir, salvo en los pacientes inmunodeprimidos o que no hayan mejorado espontáneamente después de 4 a 6 semanas del inicio de la enfermedad. ${ }^{11}$

Como conclusión, si bien la enfermedad de Ménétrier infantil es poco frecuente, debe tenerse en cuenta como parte del diagnóstico diferencial en los niños que presentan edema e hipoproteinemia, especialmente cuando se han descartado las enfermedades cardiovasculares, hepáticas y renales.

En nuestro caso, a pesar de la falta de métodos diagnósticos para identificar la etiología, la clínica del paciente, su evolución, las pruebas de laboratorio positivas para CMV y la buena respuesta al tratamiento con valganciclovir, nos permiten al menos sospechar que la causa de la enfermedad fue una infección por CMV.

\section{BIBLIOGRAFÍA}

1. Willliamson K, Park HK, Schacht R, Kaistha A. A case of Ménétrier Disease in a Child. Pediatr Emerg Care 2012; 28:277-9.

2. Blackstone MM, Mittal MK. The Edematous Toddler: A case of Pediatric Ménétrier Disease. Pediatr Emerg Care 2008; 24:682-4.

3. Sundt TM,3rd,Compton CC, Malt RA. Menetrier's disease. A trivalent gastropthy. Ann Surg 1988;208(6):694-701.

4. Cieslak Tj, MullettCT, Puntel RA, et al. Ménétrier's disease associated with citomegalovirus infection in children: report of two cases and review of the literature. Pediatr Infect Ds 1993;12:340-3.

5. Eisenstat DD, Griffiths AM, Cutz E, et al. Acute citomegalovirus infection in a child with Ménétrier disease. Gastroenterology 1995;109: 592-5.

6. Leonidas JC, Beatty EC, Wenner HA. Ménétrier Disease and citomegalovirus infection in childhood. Am J Dis Child 1973;126:806-8.

7. Megged O, Schlesinger Y. Citomegalovirus-associated protein-losing gastropathy in childhood. Eur J Pediatr 2008; 167:1217-20.

8. Occena RO, Taylor SF, Robinson CC, et al. Association of citomegalovirus with Ménétrier 's disease in childhood: report of two new cases with a review of literature. J Pediatr Gastroenterol Nutr 1993; 17:217-24.

9. Sferra TJ, Pawel BR, Qualman SJ, et al. Ménétrier Disease of childhood: role of citomegalovirus and transforming growth factor alpha. J Pediatr 1996;128:213-9.

10. Lachman RS, Martin DJ, Vawter FT. Thick gastric folds in childhood. Am J Roentgenol Radiat Ther Nucl Med 1971;112:8391.

11. Hoffer V, Finkelstein $Y$, Balter J, et al. Ganciclovir treatment in Menetrier disease. Acta Pediatrica 2003;92(8):983-5. 